\title{
A dialética do arquivo: "pensar para trás", entender o presente e mudar o futuro
}

\author{
Maria Virgínia Borges Amaral
}

\begin{abstract}
This article presents a gesture of reading that intends to understand "dialectics of the archive" from their contradictory connections substantiated in relation to history. The questions elucidated here come from theoretical foundations constructed in the path of Discourse Analysis in its dialogue with other fields of knowledge. We observed that the notion of archive, as well as memory and document occurs in close connection with effects of the movement that produced the critique of traditional history. This resulted in different philosophical and theoretical positions, building complex and controversial ways of reading the archive nowadays.
\end{abstract}

Keywords: Archive; history; collective memory; discourse analysis.

Resumo: Este artigo apresenta um gesto de leitura que procura entender "a dialética do arquivo" a partir das suas conexões contraditórias consubstanciadas na relação com a história. As questões aqui elucidadas advêm de fundamentações teóricas construídas no percurso da Análise do Discurso em sua interlocução com outros campos do saber. Verificamos que a noção de arquivo, assim como as de memória e de documento, ocorre em íntima conexão com efeitos do movimento que produziram a crítica à história tradicional. Daí resultaram posicionamentos teóricos e filosóficos diferentes, construindo formas complexas e polêmicas de leitura do arquivo nos dias atuais.

Palavras-chave: Arquivo; história; memória coletiva; análise de discurso.

Quando nos detemos a pensar sobre a natureza, ou sobre a história humana, ou sobre nossa própria atividade espiritual, deparamo-nos, em primeiro plano, com a imagem de uma trama infinita de concatenações e influências recíprocas, em que nada permanece o que era, nem como e onde era, mas tudo se move e se transforma, nasce e morre.

(ENGELS, 1987, P. 314)

Introdução

Temos prestado atenção ao debate acerca do tema arquivo no campo da Análise do Discurso. Retomamos os textos produzidos na área, iniciando por Pêcheux, evidentemente; revimos Guilhaumou e Maldidier, e fomos atualizando o processo de leitura e escrita sobre arquivo em artigos que circulam no Brasil. Supusemos que algo estaria silenciado nesse debate, embora houvesse inúmeras pistas para responder a muitas inquietações. Uma delas

1 Doutora em Linguística, professora da Universidade Federal de Alagoas (UFAL). Pesquisadora do CNPq. 


\section{Conexão Letras}

foi a referência que Pêcheux faz à historia social das mentalidades e aos métodos da "Nova História" em seu artigo de 1984, com publicação brasileira de 2011. Em seguida, encontramos Guilhaumou e Maldidier assumindo em sua prática de análise de discurso a retomada das preocupações dos historiadores das mentalidades, confrontando objetos de caráter mais abstrato, como a morte, o medo, o amor, o profano e o sagrado, com a instalação de arquivos, leitura e textos. Referiam-se, também, ao texto de Pêcheux que mencionamos.

Em autores brasileiros encontramos propósitos, bastante procedentes, de apresentar uma leitura atual de arquivo, e com essa noção, a de história, memória e documentos. As definições advêm de fundamentação teórica construída no percurso da Análise do Discurso e sua interlocução com outros pensadores, como Foucault, como o faz Nunes (2008), por exemplo. Verificamos que a noção de história, assim como a de arquivo, de memória e de documento, não ocorre desgarrada dos fundamentos teóricos e filosóficos que foram produzidos como resultados de muitas pesquisas. Continuamos inquieta e com a curiosidade aguçada, procurando entender "a dialética do arquivo", visto que desde Engels (1987, p. 316) sabe-se que a dialética "focaliza as coisas e suas imagens conceituais substancialmente em suas conexões, em sua concatenação, em sua dinâmica, em seu processo de nascimento e caducidade".

Um dos livros recentes de Slavoj Zizek (2012) tem um título curioso: Vivendo no fim dos tempos. A apresentação do livro por Emir Sader ${ }^{2}$ também nos despertou para o cerne da questão que apresentamos neste texto. Diz ele: "Vivendo no fim dos tempos faz uma descrição implacável das catástrofes que nos ameaçam, e ao mesmo tempo, critica o catastrofismo, buscando sempre o lugar onde a história pode ser revertida". É isso. Pensamos que, nestes tempos, os meios utilizados para se conhecer a realidade parecem atingidos pela catástrofe que põe em risco a sociedade. Cremos que o debate atual sobre arquivo, documentos, memória coletiva e história não se esgota com a definição e a classificação dos conceitos. Parece que há muito a fazer, pois nem tudo ainda foi dito ou suficientemente explicado.

Mobilizada pela necessidade de saber um pouco mais e encontrar a base teórica do que está se dizendo sobre a noção de arquivo, começamos a "pensar para trás"3, não no sentido de encontrar fantasmas históricos que assombram o presente, ameaçando clarear a escuridão produzida pelos fetiches da sociedade moderna. A alusão à expressão "pensar para trás" implica o sentido político revolucionário empregado por Zizek, mas, sobretudo, traz a necessidade de se conhecer as contradições e condições de produção do conjunto de saber acerca dos conceitos (arquivo, documento, memória, história) que são postos em debate no campo da Análise do Discurso. Supomos, pois, para darmos prosseguimento a nossa pesquisa, que a necessidade de se "reler o arquivo hoje" ocorre em virtude da suspeita de que as bases teóricas e filosóficas que originaram esse conceito também desestabilizam o saber aparentemente sedimentado. É isso que mobiliza o debate, no sentido de se retomar as noções de história, de memória e de arquivo, procurando a memória discursiva ${ }^{4}$ dessas expressões conceituais. Evidentemente, jamais poderíamos pretender responder a todas as questões que se nos puseram durante a nossa pesquisa. Nossa proposta é expor algumas reflexões, correndo os riscos peculiares aos processos de exposição do pensamento e reconhecendo a possibilidade de continuar o processo investigativo sobre a noção de arquivo e dos conceitos a ela relacionados.

2 Orelha do livro de Slavoj Zizek (2012).

3 Um desses flashes que uma leitura de Zizek proporciona.

4 Memória discursiva tratada como interdiscurso, como "o saber discursivo que torna possível todo dizer e que retorna sob forma do pré-construido, o já dito que está na base do dizível, sustentando cada tomada de palavra" (ORLANDI, 2002, p. 31). 


\section{Domínio de memória da noção de arquivo: uma revisão da história}

Ao pretendermos entender a dialética do arquivo, consideramos que nesta análise é importante a noção de domínio de memória. Ela representa um interdiscurso como instância de constituição de um discurso transverso (seria o caso do discurso da história das mentalidades, produzindo sentido na noção de arquivo no campo da Análise do Discurso, como procuraremos mostrar neste texto). Esse domínio de memória não aniquila a presença dos outros dois domínios (domínio de atualidade e o domínio de antecipação) que constituem a tríade conceitual, considerados por Courtine (2009) elementos operacionais da análise de discursos.

No domínio de memória está a possibilidade de delimitar um domínio das formulações-origem. "O domínio das formulações-origem não atribui, de modo algum, um 'começo' ao processo discursivo, mas constitui o lugar onde se pode determinar, no desenvolvimento do processo discursivo, o surgimento de enunciados que figuram como elementos de saber próprio a uma FD [Formação Discursiva]" (IDEM, p. 112). Toma-se, pois, o discurso do arquivo e suas relações interdiscursivas com a história e a memória como objeto de estudo deste artigo. A partir do domínio de memória deste discurso pretende-se chegar ao lugar em que se encontra a base do desenvolvimento do processo discursivo configurado pelos elementos de saber do espaço de significação ou formação discursiva na qual se inscreve o discurso do arquivo e outros conceitos correlacionados.

Comecemos pela crítica à "história tradicional" realizada por muitos pensadores e acatada por Pêcheux para formular uma teoria do discurso em que se encontrassem articuladas língua e história. Muitos historiadores analisaram o movimento que deu origem à crítica da história tradicional. Reconhecendo que grandes nomes ficarão sem menção neste texto, recorremos à crítica dos seguintes pensadores: na Inglaterra, Peter Burke (1992) e Eric Hobsbawm, (1998); na França, François Dosse (1992); nos Estados Unidos, Fredric Jameson (1996); no Brasil, Ciro Flamarion Cardoso (1988) ao lado do porto-riquenho Héctor Pérez Brignoli (1983).

Parece não haver controvérsia quanto ao entendimento de que o movimento crítico da história conhecido como Annales, originado na França no início do século XX, marcou época e se espalhou por diversas partes do mundo. Marc Bloch ${ }^{5}$ e Lucien Febvre são os nomes de referência da fundação da Escola dos Annales a partir do lançamento da revista Annales em 1929. Desse movimento, ou corrente filosófica de crítica à história, conforme demonstram os estudiosos do assunto na atualidade, persistem hoje em diversos campos de saber das Ciências Sociais alguns dos seus aspectos teóricos e metodológicos.

Os historiadores costumam classificar o movimento dos Annales em fases, e isso sugere que muitos dos estudos realizados na década de 1980 no campo da Análise do Discurso sejam legatários desse movimento. Para fornecer uma visão panorâmica das fases dos Annales, sintetizamos uma nota de Barros (2012, p. 217) que nos foi muito conveniente: a primeira fase corresponderia ao período de 1929 a 1945, marcada pela cooperação mais intensa entre Bloch e Febvre, quando o movimento dos Annales era ainda marginal às instituições historiográficas francesas ${ }^{6}$. A segunda fase inicia-se em 1946, quando Febvre

5 Marc Bloch deixou inacabado em seus papéis um trabalho de metodologia histórica composto no final de sua vida, intitulado Apologie de Histoire, o qual foi publicado em 1949 por Lucien Febvre sob o título Apologie de Histoire ou Métier d'historien, traduzido e publicado no Brasil pela Editora Zahar em 1997. Para este estudo utilizou-se a edição de 2001 .

6 Segundo Barros (2012, p. 217), “alguns autores também ressaltam uma subfase a partir de 1941, quando 
institucionaliza o movimento, integrando-se à École des Hautes Études, e a Revista dos Annales torna-se mais conhecida. É nesta fase que aparece Fernando Braudel como segundo dirigente do movimento. A partir de $1956^{7}$ torna-se primeiro dirigente dos Annales, em virtude da morte de Febvre. A partir de 1969 inicia-se a terceira fase; Braudel perde a direção do movimento, que passa a ser partilhado por um grupo de novos historiadores, entre os quais, Le Goff e Pierre Nora. Nesta fase emergem as obras de história das mentalidades e da antropologia histórica, declinando o projeto de História Total perseguido nas fases anteriores.

A escola dos Annales metamorfoseou-se com a sua enorme capacidade de adaptação às mudanças da sociedade e do pensamento. Cada geração do movimento que "pensava a história" fazia "escolhas" no universo das ideias literárias e científicas. A história, enquanto ciência, deveria estar articulada às outras disciplinas das ciências sociais (a Linguística, a Antropologia, a Sociologia, a Geografia, a Economia, a Psicologia) e fazer valer a história vinda de baixo ${ }^{8}$, uma história social que, sob vários protestos, alguns chamam de "história popular" por ter em pauta estudos sobre os conflitos sociais, a interação e estreita proximidade das massas, os estudos da história urbana como paradigma das mudanças sociais (HOBSBAWM, 1998).

A crítica à história tradicional comumente focaliza dois pontos fundamentais: o objeto da história e o papel do historiador. Em relação ao primeiro ponto, a crítica recai sobre o aspecto nodal de a história tratar o fato de forma linear - critica-se a história linear. Quanto ao segundo ponto, na abordagem tradicional o historiador "limita-se" a "estabelecer - a partir dos documentos - os 'fatos históricos', coordená-los, e finalmente expô-los coerentemente. Os 'fatos históricos' seriam aqueles fatos singulares, individuais, que 'não se repetem'; o historiador deveria recolhê-los todos, objetivamente, sem optar entre eles" (CARDOSO, 1983, p. 21). Como sugere Burke (1992, p. 12), os leitores seriam incapazes de duvidar das informações históricas, e isso ocorre porque "a história tradicional oferece uma visão de cima, no sentido de que tem sempre se concentrado nos grandes feitos dos grandes homens, estadistas, generais ou ocasionalmente eclesiásticos. Ao resto da humanidade foi destinado um papel secundário no drama da história".

Sabemos, contudo, que não é possível declinar dos procedimentos técnicos para a seleção e classificação dos fatos/dados documentados, mas é necessário contextualizar o fato aparentemente inerte em um documento. Conforme Cardoso (IDEM, p. 23), é necessário "situar os documentos no tempo e no espaço, classificá-los, criticá-los quanto a sua autenticidade e credibilidade". E, acrescente-se a essa questão metodológica, que essa atividade classificatória de documentos já não é uma atividade exclusiva nem única do historiador, como o era na vertente positivista da história.

Verifica-se a presença de fortes traços positivistas nos estudos históricos atuais, apesar dos avanços das pesquisas que tratam da linguagem ao lado da história, tidas como pontos centrais da Escola dos Annales. Dosse (1992) reconhece que a visão positivista de história perdura como "crônica de acontecimentos", o que nos leva a pensar nas posturas "conservadoras" que persistem nos estudos atuais sobre história, arquivo, documentos etc.

Marc Bloch cai na clandestinidade em função da ocupação nazista da França e Febvre passa a dirigir a Revista dos Annales sozinho".

7 A entrada de Braudel como dirigente dos Annales em 1959 caracterizaria uma subfase deste período de 1946 a 1969, quando predomina um modelo historiográfico sob a égide da Historia Econômica e do modelo estrutural (IDEM).

8 Refere-se à tentativa de muitos historiadores escreverem a história de pessoas das classes inferiores. É um conceito que tem suas bases filosóficas de inspiração marxista britânica do século XIX, mas que ganha maior repercussão a partir do século XX com os historiadores dos Annales (SHARPE, 1992, p. 39). 
Por isso tudo, é interessante registrar que o movimento dos Annales avançou por caminhos diversos, resultando em muitas contradições, inclusive com fragilidades teóricas que caracterizavam suas propostas de revisão do sentido de história. Segundo Dosse, o sentido de história desembocou no sentido de uma história "quase imóvel", contradizendo princípios filosóficos que originaram os Annales, destituindo a relação dialética entre passado, presente e futuro, e desfigurando a essência da história numa perspectiva de totalidade para torná-la fragmentada - uma "história em migalhas"

A história da escola dos Analles não é uma história imóvel. Bem ao contrário, ela se adapta com sucesso às mutações sucessivas de nossa sociedade no decorrer do século XX e resiste com a mesma vitalidade aos assaltos das ciências sociais vizinhas e concorrentes. [...]. Entre os Annales dos anos 30 e os dos anos 80, pode-se localizar certo número de continuidades e de descontinuidades. A mesma negação do aspecto político dos Annales desde seu nascimento, o mesmo procedimento de captação das ciências sociais, de tudo que aparece como novo, a mesma terceira via entre a história tradicional historicista e o marxismo ossificado, no qual os Annales preencherão os vazios ao investir em domínios inexplorados, e, ao mesmo tempo, quebra-mares de resistência ao marxismo e substituto desse último: não ideologia, mas mentalidade, não materialismo, mas materialidade, não dialética, mas estrutura... (DOSSE, 1992, p. 250). (grifo nosso).

Para Dosse, a combinação de história econômica e história das instituições políticas seria uma estratégia do mundo herdeiro das mudanças que marcaram a sociedade da década de 1960: "a história é, nesse momento, mistura de demografia, de curvas econômicas e de análise das relações sociais" "11. O triunfo foi do economicismo que privilegiou ainda mais o mecanicismo dos dados, "chega a minorar o papel do homem, sua capacidade de fazer história, de ser nela o sujeito ativo e consciente" (DOSSE, 1992, p. 104). Dosse, diferentemente do Hobsbawm, como poderemos ver a seguir, não reconhece nenhuma aproximação das ideias da história social com as ideias marxistas. Para ele houve uma substituição de termos, que não é inconsequente: "não ideologia, mas mentalidade, não materialismo, mas materialidade, não dialética, mas estrutura... ” Isso também nos é familiar!

\section{0 marxismo nos Annales e a história das mentalidades}

Alguns críticos do movimento dos Annales acreditam que a aproximação do marxismo no início do movimento nas décadas que precederam a "Nova História"12 perdeu-se no

9 De onde procede a crítica de Foucault à história e à análise da função do arquivo: da ressurreição do enunciado inerte, o que descaracterizaria essa imobilidade da história. "É o arquivo que faz com que todas as coisas ditas não se acumulem indefinidamente em uma massa amorfa" (1987, p. 149).

10 Título do livro de Dosse (1992): "A história em migalhas: dos "Annales" à "Nova História".

11 Dosse (1992, p.104) lembra que "a valorização da demografia responde à possibilidade de integração dos dados em uma quantificação maciça, corresponde a um quadro de conceituação que se tornou possível por uma técnica, a do computador”. Entende-se, pois, a menção de Pêcheux (1997) à permanência desses critérios da informática nas práticas dos historiadores, seja valorizando a quantidade, seja valorizando a qualidade dos dados.

12 Na década de 1970, novos seguidores das ideias originadas nos Annales apresentaram-se como continuadores de Marc Bloch e Lucien Lebvre, agora acrescentando as ideias de Braudel, a Nova História. Essa fase dos Annales, no final na década de 1970, teve entre as suas lideranças o nome J. Le Goff. Na Nova História, a história das mentalidades ocupou um espaço bastante significativo, logrando êxito maior ao se estabelecer a interlocução com as ideias de Foucault. 


\section{Conexão Letras}

momento em que Braudel ${ }^{13}$ assumiu a "escola", dando-lhe novos direcionamentos. Seria interessante identificar o que de fato restou da interlocução dos Annales com o marxismo, bem como o que afetou a Análise do Discurso que pode restabelecer uma perspectiva crítica do discurso documental e do arquivo hoje. Talvez possamos discutir essa questão em outra oportunidade, não neste artigo. Para o momento, vale a pena rever alguns pontos dos estudos de Hobsbawm (1992) sobre a História, as mudanças ocorridas a partir da crítica à história tradicional, de onde podemos abstrair elementos significativos para compreender a discussão que se faz hoje em Análise do Discurso.

Hobsbawm viveu a experiência da aproximação do marxismo ao movimento dos Annales na Inglaterra dos anos de 1930. Declarando-se marxista, acrescenta que foi no terreno da história econômica e social que ele e os pensadores dos Annales se encontraram: "Os jovens marxistas daqueles tempos descobriram que a única parte da história oficial que fazia algum sentido para eles, ou pelo menos que podiam utilizar, era a história econômica, ou a história econômica e social. Dessa forma, foi por meio dela que a junção foi feita" (HOBSBAWM, 1992, p. 194). Para Hobsbawm, era evidente a curiosa confluência, via história econômica, entre o marxismo e a escola francesa até a década de 1950, quando Fernand Braudel influenciou o redirecionamento dos Annales.

As crises pelas quais passou a escola dos Annales, na década de 1950, fê-la tomar novos rumos; as ideias difundidas por grupos diferentes de historiadores fizeram surgir novas possibilidades, inclusive o movimento conhecido como história das mentalidades, que, ainda, segundo Hobsbawm, ganhou na Inglaterra uma conotação diferente da francesa. Nesse processo, pensadores como Peter Burke e Edward Thompson tentaram mostrar a diversidade de sentidos que a história teria adquirido nos vários grupos que a criticavam. Hobsbawm se declara um pensador preocupado em entender a história das mentalidades

como um problema não de empatia histórica ou arqueológica, ou se preferirem,de psicologia social, mas da descoberta da coesão lógica interna de sistemas de pensamento e comportamento que se ajustem ao modo pelo qual as pessoas vivem em sociedade em sua classe particular e em sua situação particular da luta de classes, contra aqueles de cima, ou, se preferirem, de baixo (IDEM, p. 200).

Segundo esse autor (IDEM, p. 95), nos últimos dez anos agruparam-se algumas questões em torno do trabalho do historiador social. Ele se refere, provavelmente, ao período de 1988 a 1998, mas acreditamos que persista até nossos dias. É esse o complexo de questões: 1. demografia e parentesco; 2. estudos urbanos; 3. classes e grupos sociais; 4. a história das "mentalidades" ou consciência coletiva ou da cultura na acepção dos antropólogos; 5. a transformação das sociedades (por exemplo, modernização ou industrialização); 6 . movimentos sociais e fenômenos de protestos sociais.

Para Hobsbawm, os dois primeiros grupos se institucionalizaram como campos de saber, assim como a história urbana, que possui unidade tecnologicamente determinada, muitas vezes com sua documentação específica. Os outros grupos de questões estão em desenvolvimento com a premissa de que nenhum estudo da sociedade é possível sem levar em conta todos os aspectos da existência social. Essas temáticas ecoam nas pesquisas de Análise do Discurso. Todas nos são muito familiares. Diríamos que no tópico 4 poderí-

13 Hobsbawm (1998, p. 196) escreve: “[...] e espero que Fernand Braudel me perdoe por sublinhar o fato de que ele não é marxista", levando a crer que na aproximação entre os ingleses e os pensadores franceses se deu numa conexão com as ideias de Bloch e Lebvre que indicavam uma certa tendência marxista de fazer a História Social. 
amos lembrar o conceito de "memória coletiva", numa combinação com "história das mentalidades" e cultura.

Hoje, os propósitos da primeira fase dos Annales reaparecem mesclados por outras abordagens ditas modernas, com o intuito de reconstituir a história social, de retomar o sentido de história, memória e arquivo. Reaparecem em pesquisas atuais da Análise do Discurso, atestando a evolução da concepção clássica de arquivo. Do "recorte de séries textuais", numa abordagem de história serial, às vezes confundidas com história quantitativa ${ }^{14}$, a noção de arquivo expande-se. Encontra acento na revitalizada história das mentalidades, que hoje se acha num campo de inúmeras preocupações conceituais, dada a complexidade que encerra a noção de arquivo quando relacionada à história.

\section{A história das mentalidades revista na Análise do Discurso}

Guilhaumou e Maldidier (1997, p. 164) indicaram, em um dos seus textos datado da década de 1980, a retomada de questões da história das mentalidades: "Nossa prática de análise do discurso retoma as preocupações dos historiadores de mentalidade, que na construção de objetos como a morte, o medo, o amor, o profano e o sagrado, instalam, pela confrontação de séries arquivistas, regimes múltiplos de produção, circulação e leitura de texto" (grifo nosso). Para Guilhamou (2009), os anos 1980 marcam uma virada - "virada interpretativa" (IDEM, p. 32) - na prática da análise de discursos realizada ao lado da história, tornando a Análise do Discurso uma disciplina interpretativa. O discurso passa a ser visto não somente como aquele que anuncia a ação relatada, mas como, também, aquele que produz a ação. Isso afeta sobremaneira a noção de arquivo. A incorporação do arquivo na prática de análise de discurso tornou mais complexa a investigação do "historiador do discurso" 15 .

Pêcheux, em 1984, referia-se a essas abordagens discursivas incorporando a discursividade do arquivo e dos documentos na linha da história das mentalidades; apontava, então, para a superação da tradicional perspectiva de enunciado documental. Esse procedimento significaria "juntar e interpretar séries textuais ${ }^{16}$ em que se inscrevem discursivamente as figuras da infância, da loucura, da morte ou da sexualidade, próprias a esta ou àquela época, e supunha abandonar as certezas associadas ao enunciado documental" (PECHEUX, 2011, p. 285) ${ }^{17}$. (Grifo nosso).

14 Sobre os elementos conceituais História Serial e História Quantitativa no movimento dos Annales, ver o trabalho de Barros (2012).

15 Expressão usada por Guilhaumou (2009).

16 Perguntamo-nos se "séries textuais" teria alguma relação com os encaminhamentos de história serial, uma proposta que indica uma mudança na concepção clássica de arquivo. A esse respeito, indicamos o estudo de Barros (2012).

17 Pêcheux trata sobre essa questão em seu artigo, publicado na revista Mots, 9, de 1984, traduzido para o português com o título "Sobre os contextos epistemológicos da Análise do Discurso", incluído na coletânea de textos de Pêcheux organizada por Eni Orlandi em 2011, pela editora Pontes. Esse trabalho de Pêcheux resulta da produção do Projeto de Pesquisa Cooperativa do Programa - RCP / ADELA - Análise de Discurso e Leitura de Arquivo -, um programa criado em janeiro de 1982 que visava o desenvolvimento dos trabalhos de análise de discurso "com uma ligação estreita e coerente com as preocupações sócio-históricas, a pesquisa linguística e o desenvolvimento da informática textual”. A RCP era estruturada em três grandes áreas: Arquivo sócio-histórico, Pesquisas linguísticas sobre discursividade, Informática em análise do discurso (MALDIDIER, 2003, p. 79). Desta época também provém a discussão em torno do texto de 1982, "Lire l'archive aujourd'hui", Archives et documents de la Société d'histoire et d'épistémologie des sciences du langage (Saint-Cloud), 2, 1982, p. 35-45. Publicado em português: Orlandi, Eni. Gestos de leitura: da história no discurso, 1997. 
Anuncia-se na experiência investigativa dos analistas de discurso outro gesto de leitura de arquivo. Uma abordagem discursiva dessa atitude interpretativa exigiria algumas atitudes que conduzissem à superação do enfoque tradicional para se constituir, conforme escreve Pêcheux (1997, p. 57) "um espaço polêmico das maneiras de ler o arquivo, uma descrição do trabalho do arquivo enquanto relação do arquivo com ele mesmo, uma série de conjunturas, trabalho da memória histórica em perpétuo confronto consigo mesma". Esse gesto de leitura, a nosso ver, considera a dialética do arquivo que, em sua condição de aparente inércia, age e gera mudanças no processo de produção/reprodução sócio-histórica. Trata-se, pois, de uma "leitura com aderências históricas". De uma "leitura literal" que configuraria a "apreensão-do-documento" passa-se a uma leitura interpretativa de arquivo. A leitura de arquivo implica um "trabalho anônimo, fastigioso, mas necessário, através do qual os aparelhos do poder de nossas sociedades geram a memória coletiva" (Pêcheux, 1997, p. 57) ${ }^{18}$. (Grifo nosso). Com esse gesto de leitura, o arquivo extrapola a sua condição de banco de dados, de "campo de documentos pertinentes e disponíveis sobre uma questão”, como indica Pêcheux (Idem).

Os estudos acerca do arquivo circulam em basicamente duas direções: para demonstrar sua procedência e para contestar as perspectivas inovadoras em torno de sua utilização nos procedimentos de elaboração da memória coletiva. Aqui, a nosso ver, dá-se o encontro da noção de arquivo derivada das perspectivas da história social das mentalidades e, portanto, pagando algum tributo aos Annales da primeira fase, em sua crítica à história inerte, com a Análise do Discurso. Pêcheux (2011, p. 284) aproxima a história das mentalidades da análise do discurso. Assim, “[...] a história social das mentalidades, dos sistemas de pensamentos ou das ideologias constitui uma abertura que, por múltiplos caminhos, desenvolveu-se consideravelmente no último período: esta abertura supõe trabalhar sobre os textos de outra maneira, colocando em causa a transparência da língua”.

Verificamos a necessidade de se retomar criticamente a história das mentalidades em relação às suas fontes teóricas e filosóficas. O conceito de mentalidades (mentalité) foi de suma importância para os historiadores que tentaram construir uma história do "mundo mental" das pessoas de classe inferior; isso configura o princípio de se fazer "história vinda de baixo" e a interlocução com a psicologia, com a etnologia e, mais abrangentemente, com a antropologia. Daí dizer-se que a história das mentalidades agregava-se a uma área de saber advinda de disciplinas "estranhas à história". A mudança de direção dos historiadores rumo às mentalidades prefigura, segundo constata Dosse (1992, p. 84), "as evoluções futuras e o avanço irresistível dos anos 60".

\section{Arquivo e documentos na história revisitada}

Na década de 1960, as abordagens discursivas do arquivo configuravam-se como uma historiografia ${ }^{19}$ documental, tratada, sobremaneira, do ponto de vista de uma prática "literária" requerida pela profissão de historiadores. Pêcheux (2011, p. 284), ao analisar

18 A noção de memória coletiva passou por muitas transformações desde que foi cunhada por Maurice Halbwachs na primeira metade do século XX, no livro intitulado Memória Coletiva, com publicação no Brasil na década de 1960. Superando a concepção tradicionalista de memória coletiva advinda de Halbwachs, Bloch, com o espírito dos Annales, entende que "os estudos da memória coletiva deveriam estar voltados às causalidades inerentes às ações sociais, não podendo ser derivadas de estudos empíricos sobre padrões de comportamentos" (CASADEI, 2010, p. 158).

19 Um termo muitas vezes usado pelos pensadores franceses, no sentido de "história da história" (RICOEUR, 2007, p. 413). Ver essa concepção de historicidade em Le Goff (1990). 
essa questão, sugere que tais abordagens persistiam na década de 1980: “combinando, por exemplo, a história econômica e a das instituições políticas, permanecem, marxistas ou não, qualitativas ou quantitativas, inscritas na mesma tradição".

A "mesma tradição" da qual emerge uma historiografia documental teria sido questionada, e a história social das mentalidades, dos sistemas de pensamentos ou das ideologias teria dado abertura a novas possibilidades de se trabalhar os arquivos discursivamente. Comumente, trata-se a noção de arquivo associada às de documento, memória e história. Cada um desses conceitos tem particularidades que distinguem um do outro, entretanto em cada um deles também estão relacionados os conteúdos dos demais. Nesse sentido, será quase impossível, em uma abordagem discursiva, interpretar um desses conceitos sem que seja, essa interpretação, atravessada pela memória discursiva dos outros. Todas essas noções - de arquivo, de documento, de memória e de história -, retomadas pela Análise do Discurso, são problematizadas, questionando-se o sentido literal dessas expressões. Esse debate tem recuperado a historicidade desses conceitos, contribuindo para avançar no conhecimento da história dos discursos constituintes da memória coletiva na contemporaneidade.

A noção de documento, por exemplo, passa por várias transformações. Da expressão titres et documents (títulos e documentos), difundida no século XVII no vocábulo legislativo francês, o termo documento associa-se à expressão moderna de testemunho histórico, no século XX. No final do século XIX e início do século XX, o documento passa a ser visto como o fundamento do fato histórico, uma prova objetiva da história, forma científica da memória coletiva, a quem serviam os dois tipos de materiais: o documento e o monumento (LE GOFF, 1990). Por isso tem-se em Foucault, como lembra Pêcheux (2011, p. 285), um tratamento explícito de documento como monumento. "Isto é, como um vestígio discursivo em uma história, um nó singular em uma rede" (IDEM).

Mas na evolução do conhecimento histórico, o documento (que seria material escolhido pelo pesquisador/historiador) triunfa sobre o monumento (considerado como herança do passado. Em Le Goff (1990, p. 462) verificamos que "De fato, o que sobrevive não é o conjunto daquilo que existiu no passado, mas uma escolha efetuada quer pelas forças que operam no desenvolvimento temporal do mundo e da humanidade, quer pelos que se dedicam à ciência do passado e do tempo que passa, os historiadores". Esta concepção de documentos se resume no que foi pensado por Bloch: os "documentos são vestígios" de uma história; "o vocabulário dos documentos não é, a seu modo, nada mais que um testemunho: precioso, sem dúvida, entre todos; mas, como todos os testemunhos, imperfeito; portanto, sujeito à crítica" (BLOCH, 2001, p. 141) ${ }^{20}$.

Ainda nessa evolução conceitual, a concepção de enunciado documental, por exemplo, que estaria associada à de enunciado inerte, fechado em si mesmo, teria sido superada pela concepção de discurso documental, documento de arquivo, conforme esclarece Nunes (2008, p. 82): "Ler os documentos de arquivo conduz a explicitar os gestos de interpretação que subjazem à sua elaboração, evitando-se reproduzir uma história já dada, fixada, e mostrando seu processo de construção". Disso decorre a perspectiva de uma leitura interpretativa de discursos documentais e arquivos requisitada pela Análise do Discurso hoje, como se vê nos debates atuais.

Nessa linha de pensamento, o documento é tido como uma materialidade da história, não uma materialidade inerte, mas uma materialidade móvel, dinâmica, dialética, sustentada

20 Aqui se tem a noção de testemunho, o que mereceria uma discussão mais aprofundada. 
em sua própria contradição - partindo-se do presente, "pensa-se para trás" e se volta ao momento atual, para compreender e explicar o presente. O arquivo, pensado em relação ao documento, pode ser entendido como concebe Foucault (1987, p. 149): "a lei do que pode ser dito, o sistema que rege o aparecimento dos enunciados como acontecimentos singulares". E os "acontecimentos singulares" seriam, em nosso entendimento, transformados em documentos.

Ainda conforme Foucault (IDEM), o arquivo não é o que recolhe a poeira dos enunciados [documentos] que novamente se tornaram inertes e aguardam o milagre da ressurreição. $\mathrm{O}$ arquivo define o modo da enuncialidade do documento. "Longe de ser o que unifica tudo que foi dito no grande murmúrio confuso de um discurso [...], é o que diferencia os discursos em sua existência múltipla e os especifica em sua duração própria” (IDEM).

Guilhaumou (2009, p. 125), ao considerar a perspectiva de arquivo aberta por Foucault, retoma a discussão de sujeito, objeto e conceitos como funções derivadas do enunciado e trata de uma "dispersão arquivística" no interior de um "dispositivo acontecimental". Escreve: "o arquivo não é um simples material de onde se extraem fatos de maneira referencial; ele participa, sobretudo, de um gesto de leitura no qual se atualizam as configurações significantes, os dispositivos de significações de enunciados atestados" (IDEM). Acrescenta que a descrição de um arquivo, mesmo que marcado por uma época, é sempre aberta, "ainda que a frase historiográfica se esforce em fechá-lo".

Com essas particularidades que distinguem o arquivo do documento, e ao mesmo tempo os aproximam, unindo-os no "sistema da discursividade", avançamos no complexo das questões atestadas. Intentamos entender o arquivo como aquilo que "a partir de uma posição dada, numa conjuntura dada, determinada pelo estado de luta de classes, determina o que pode e deve ser dito" - uma formação discursiva (PECHEUX, 1988, p. 160). Espaço discursivo que é um sítio de significância ${ }^{21}$ em que são articulados os enunciados que produzem sentidos; no caso específico da função social do arquivo, tem-se a produção da memória coletiva.

\section{Concluindo}

É evidente que o desenvolvimento das ciências sociais hoje requer o conhecimento de indicadores fornecidos pelos organismos dotados de meios eficazes, alimentados pelo desenvolvimento de novas tecnologias. A estatística e a demografia tornam-se áreas especificas auxiliares do poder político. Este também seria o caminho que levaria à identificação da vertente de leitura de arquivo que serve aos interesses dos aparelhos do poder para gerar a memória coletiva. Com isto tem-se na sociedade uma divisão social do trabalho de leitura para o tratamento dos textos e controle da memória de um povo. A leitura de arquivos, assim como a história como ciência, apresenta um discurso correspondente à sociedade. Os discursos históricos articulam-se às diferentes fases da sociedade, períodos de adaptação ao desdobramento do dispositivo social (DOSSE, 1992, p. 253). Na Idade Média, por exemplo, os clérigos dominavam a sociedade impondo sua visão de mundo ${ }^{22}$,

21 Para usar um termo empregado por Orlandi (1998, p. 13) na discussão sobre Formação Discursiva.

22 Pêcheux (1997, p. 57) lembra o processo de divisão de leitura que se origina na Idade Média; alguns clérigos eram autorizados a ler, a falar e escrever em seus nomes; eram portadores de leitura e obra própria; todos os outros eram escrivães, copistas e "contínuos" (moços de recado, office-boys, profissionais que trabalham em escritórios, transportando correspondências, documentos, objetos dentro e fora das instituições) particulares e públicos, constituídos de uma prática de leitura que impunham ao sujeito o seu apagamento na instituição que o emprega. Isso ainda podemos ver nos nossos dias. 
mas nos períodos seguintes o discurso histórico adapta-se às mudanças: do poder do mosteiro à cidade, do castelo ao Estado, a história vai se modificando para melhor corresponder ao poder dominante (IDEM). Assim como na ficção de Orwell, a história contribui para a reprodução da condição de dominantes e dominados na sociedade, e ao povo cabe um naco de conhecimentos furtivos: "Quem controla o passado, controla o futuro; quem controla o presente, controla o passado" (ORWELL, 1984, p. 36).

Muitas abordagens de arquivo vinculadas à história tendem a obscurecer o processo contraditório constituinte da natureza do arquivo, aniquilando a dialética entre passado, presente e futuro. Muitas vezes a história - e o arquivo também - é destituída dessa contradição e torna o presente "desmemoriado", apagando o sentido que os acontecimentos poderiam dar à vida. $\mathrm{O}$ arquivo, numa perspectiva de historicidade, não implica uma representação do passado, nem uma representação do futuro, visto que a historicidade, como entende Jameson (1996, p. 290), pode ser definida como "uma percepção do presente como história".

A negação de uma historiografia dialética parece um paradoxo: como fazer história que não seja de fatos passados? Esse era o desafio para os historiadores críticos que deram origem aos Annales: fazer "uma história que se acelera ao mesmo tempo que nos escapa", como diz Dosse (1992, p. 14). O desafio, hoje, estaria em lidar com a velocidade das informações e fazer a história do presente, assim como do passado, para um futuro diferente. Isso porque "a informação renova-se a cada dia, e um conjunto de acontecimentos ao mesmo tempo rápido e urgente desenvolve-se sobre a vasta cena mundial" (Idem, ibidem). Em virtude desse aceleramento dos acontecimentos é que nos escapa a capacidade de interpretar a dialética do arquivo, pois a vida acontece à margem da história, e "nós mais a sofremos do que a vivemos" (DOSSE, Idem, ibidem).

\section{Referências}

BARROS. José D'Assunção. A história serial e a história quantitativa no movimento dos Annales. História Revista. Revista da Faculdade de História e do Programa de Pós-Graduação em História da Universidade Federal de Goiás, v. 17, n. 1 http://www.revistas.ufg.br. 2012.

CARDOSO, Ciro Flamarion S. e BRIGNOLI, Hector Perez. Os métodos da história. Rio de Janeiro: Edições Graal, 1983.

CARDOSO, Ciro Flamarion S. Ensaios racionalistas. Rio de Janeiro: Campus, 1988. CASADEI. Eliza Bachega. Maurice Halbwachs e Marc Bloch em torno do conceito de memória coletiva. Revista Espaço Acadêmico no 108, março de 2010. p. 153-161. Disponível em http://www.periodicos.uem.br. Acesso em fevereiro de 2014.

COURTINE. Jean-Jacques. Análise do Discurso político: o discurso comunista endereçado aos cristãos. São Paulo: EdUFSCar, 2009.

BURKE, Peter. Abertura: A Nova Historia seu passado e seu futuro. In. BURKE, Peter (org.). A escrita da história: novas perspectivas. São Paulo: Editora UNESP, 1992. p. 7-37.

BLOCH, Marc Apologia da história ou o oficio de historiador. Rio de Janeiro: Jorge Zahar Ed. 2001.

DOSSE, François. A história em migalhas: dos "Annales" à "Nova História. São Paulo: Ensaio; Campinas, SP: Editora da UNICAMP, 1992. 


\section{Conexão Letras}

ENGELS, Friedrich. Do socialismo utópico ao socialismo cientifico. In. Karl Marx e Friedrich Engels. Obras Escolhidas. São Paulo: Editora Alfa-Omega, volume 2, s/d. p. 281-336.

FOUCAULT, Michel. A arqueologia do saber. Rio de Janeiro: Forense Universitária, 1987.

GUILHAUMOU, J. e MALDIDIER, D. Efeitos do arquivo. Análise do discurso no lado da História. In. ORLANDI, E. (org.). Gestos de Leitura: da história no discurso. Campinas, SP: Editora da UNICAMP, 1997. p. 163-188.

GUILHAUMOU, Jacques. Linguística e História: percursos analíticos de acontecimentos discursivos. São Carlos: Pedro \& João Editores, 2009.

HOBSBAWM, Eric. Sobre história. São Paulo: Companhia das Letras, 1998.

JAMESON, Fredric. Pós-Modernismo - a lógica cultural do capitalismo tardio. São Paulo: Ática, 1996.

LE GOFF, Jacques. História e memória. Campinas, SP: Editora da UNICAMP, 1990.

MALDIDIER, Denise. A inquietação do discurso - (Re)ler Michel Pêcheux hoje. Campinas, SP: Pontes, 2003.

NUNES, José Horta. O discurso documental na história das ideias linguísticas e o caso dos dicionários. Alfa, São Paulo, 52, 2008. p. 81-100. Disponível em seer.fclar.unesp.br/ alfa/article. Acesso em fevereiro de 2014.

ORLANDI. Eni P. Introdução. A leitura proposta e os leitores possíveis. In ORLANDI. Eni P. (org.) A leitura e os leitores. Campinas, SP: Pontes, 1998.

2002.

. Análise do discurso: princípios e procedimentos. Campinas, SP: Pontes, 4. ed.,

ORWELL, George. 1984. São Paulo: Ed. Nacional. 1984.

PÊCHEUX, Michel. Semântica e Discurso: uma crítica à afirmação do óbvio. Campinas, SP: Editora da UNICAMP, 1988.

. Ler o arquivo hoje. In. ORLANDI, E. (org.). Gestos de Leitura: da história no

discurso. Campinas, SP: Editora da UNICAMP, 1997. p. 55-66.

. Sobre os contextos epistemológicos da análise do discurso. In. ORLANDI, E.

(org.). Análise de Discurso: Michel Pêcheux. Campinas, SP: Editora da UNICAMP, 2011. p. 283-294.

RICOEUR, Paul, A memória, a história, o esquecimento. Campinas, SP: Editora da UNICAMP, 2007.

SHARPE, Jim. A história vista de baixo. In. BURKE, Peter (org.). A escrita da história: novas perspectivas. São Paulo: Editora UNESP, 1992. p. 39-62.

ZIZEK, Slavoj. Vivendo no fim dos tempos. São Paulo: Boitempo, 2012. 